\title{
The Effect of Mediated Cognitive Strategies and Parental Involvement on Developing English Literacy and Self-efficacy of Saudi international
} school Students

\author{
Dr. Safaa, M. Abdelhalim \\ Associate professor of Curriculum \& EFL Teaching Methods, \\ Faculty of Education, Helwan University \& Faculty of Language \\ and Translation, Imam University, Saudi Arabia
}

\begin{abstract}
This study traced the development of English Literacy skills and self-efficacy of third grade struggling readers and writers which result from Mediated Cognitive Strategies (MCS) instruction through Gradual Release of Responsibility (GRR) Model and parental involvement in a team approach based program. Twenty five third grade struggling readers and writers with diverse cultural and linguistic backgrounds, selected from two different Saudian international schools, participated in this experiment for 14 weeks. Students received the cognitive strategy instruction for the full length of the intervention while using culturally relevant texts at the third grade level. Students were assessed for their literacy skills at pre and post intervention using literacy achievement pre-posttests. Further, the students were assessed for their self-efficacy in reading and writing using self-efficacy scale and focus group interviews as pre and post intervention. The results of the study showed that there is a significant effect of the proposed program on accelerating the development of the literacy skills and self-efficacy of the third grade struggling readers and writers. Though, there was not a correlation between developing literacy skills and self-efficacy belief for the treatment group students.
\end{abstract}

Keywords: Cognitive Strategies Instruction, Gradual Release of Responsibility (GRR) model, Balanced Literacy, self-efficacy, parental involvement 


\section{Introduction}

"All young children need to learn to read and write in order to have a chance in school and later in life" Espinosa $(2011,1)$.

Literacy is the basis of instruction for all academic subjects. It is essential for living satisfactory and rewarding lives, and participating as active and informed citizens in society. Reciprocally, the inabilities to read and write negatively impact the quality of one's life (Oeideachais \& Scileanna, 2011, 1). The development of students' literacy skills in primary schools is not just the responsibility of language teachers. Teachers of all subjects have an essential role to play in developing and consolidating students' mastering of literacy skills.

Acquiring literacy skills is important for all students, especially for international schools struggling readers and writers, due to the increasing demands of the curriculum and complexity of texts. Struggling readers are considered passive learners, they have difficulties regulate their learning, monitor their reading, and face difficulties applying appropriate reading comprehension strategies. Their lack of strategic learning skills impacts their school related performance, and thus creates additional issues, such as, motivational, self-efficacy and engagement problems. Effective instruction for struggling readers and writers is currently at the forefront of literacy studies. Research on what motivates and engages struggling readers and writers is accumulating rapidly (Fink \& Samuels, 2008; Paterson \& Elliolt, 2006; Potenza-Radis, 2008). Fisher Douglas (2006) stressed that all students need purposeful instruction in reading and writing skills and strategies, motivation to read, access to a wide variety of texts, 
and authentic opportunities to read and write both inside and outside of school.

Literacy is much more than reading, writing as highlighted by Oeideachais and Scileanna $(2011,8)$

Traditionally we have thought about literacy as the skills of reading and writing; but today our understanding of literacy encompasses much more than that. Literacy includes the capacity to read, understand and critically appreciate various forms of communication including spoken language, printed text, broadcast media, and digital media.

Gheith (2006, 6) stressed also that literacy encompasses many comprehensive human activities e.g. learning how to learn, how to organize knowledge, how to select and reflect appropriate information in a given context. Students have to be aware of the importance of reading in their everyday life. Thus literacy becomes a form of critical thinking, a form of lifelong Education.

Gajria et al., (2007) highlighted that the end goal for reading is intact comprehension; thus, it is not limited to phonological awareness, decoding skills, and visual word recognition. Potenza-Radis $(2008,1)$ added that in order to become successful readers, not only do students need quality instruction but they also require plentiful opportunities to read and write for real purposes. Frey and Fisher (2006) stressed that students need to develop their expertise in all aspects of reading and writing, including oral language, phonemic awareness, phonics, vocabulary, fluency, and comprehension. Unfortunately, instead of receiving these authentic literacy experiences, research has demonstrated that struggling readers and writers 
are more likely to receive instruction that emphasizes isolated, decontextualized skills (Buehl, 2005; Fisher \&Frey, 2003; Williams, 2001). Accordingly, the focus of the current study is to promote Balanced Literacy teaching and learning where the technical aspects of reading and writing are taught in the context of making and extracting meaning through/from text. Balanced literacy is a curricular methodology that integrates various modalities of literacy instruction. The balanced literacy approach is characterized by explicit skill instruction and the use of authentic texts. This notion of balance is based on the fact that "there is no single best method to ensure literacy for all'. As the most valuable activity for developing a skill is to involve the learner in understanding and practicing this skill, strategy instruction is an important component of a balanced literacy program.

Brown (2008) assured that cognitive strategy instruction can be effective in this area. Fisher and Frey (2013) added also that multiple strategies can be more effective than one single strategy because reading comprehension calls upon a variety of cognitive skills. Thus, struggling readers can benefit from mediated cognitive strategy instruction, appropriate material selection, and social learning (Williams, 2001; Potenza-Raids, 2008). Through strategy instruction, teacher carries out a well-planned comprehensive literacy program that reflects a gradual release of responsibility from the teacher to the students. The role of the teacher shifts from authority to guide and facilitator. Frey and Fisher $(2010,84)$ declared that this type of instruction that bases on scaffolding ensures that students develop the cognitive and meta-cognitive processes necessary to learn to read and read to learn. 
The idea of scaffolding is traced back to Vygotsky (1978) who introduced the world to the zone of proximal development (ZPD). According to Vygotsky learners operate on two levels: the "actual developmental level" and the "potential developmental level." The ZPD is "the distance between the actual developmental levels as determined by independent problem solving and the level of potential development as determined through problem solving under adult guidance or in collaboration with more capable peers" (p. 86). Pearson \& Gallagher (1983) recommended that a common way that teachers can scaffold struggling readers and writers is to use a gradual release of responsibility model. The gradual release of responsibility model of instruction has been documented as an effective approach for improving literacy achievement (Fisher \& Frey, 2007), and literacy outcomes for English language learners (Kong \& Pearson, 2003). Moreover, Lee $(2008$, 1) pointed out that home culture and practices largely influence and sustain language and that literacy learning is a social and cultural process. Some researchers have recently also found that home support is a major factor in fostering higher achievement especially when parents read regularly to their children, promote positive attitudes toward literacy development, and enhance their children's oral language skills (e.g. Dever \& Burts, 2002; Opitz, Rubin, \& Erekson, 2011). Hoover-Dempsey and Sandler (1995, cited in Morrison, Morrison, Storey and Zhang (2011, 21) declared that through interacting with parents and participating in coreading activities, primary students acquire the value and function of learning and literacy practices, which serve as a base to assist school learning.

\section{5}


Literature review revealed that only Few studies have dealt with the relationship between parental involvement and literacy learning in EFL context though largely conducted with monolingual families (e.g. Anderson, 2000; Roberts, Jurgens, \& Burchinal, 2005) and bilingual families in ESL contexts (e.g. August \& Shanahan, 2006). Although English language learning and teaching in EFL contexts differs from ESL environment concerning the aim of learning English, resources available, learning and teaching cultures and educational policy on English education (Chowdury, 2003). Further, parents' support for their children's English language learning is much more complicated in such context as parents usually are not proficient in the language and limited resources are available in societal context. Accordingly, providing parents with a variety of resources and strategies to promote literacy at home is critical.

To meet the above mentioned research limitations, the current study adopts a team based approach, by supporting the crucial roles of parents and teachers in supporting the literacy development of EFL struggling students. This study is also grounded in Mediated cognitive strategies instruction and the concept of scaffolding, represented in the steps of the Gradual Release of Responsibility model which encourages adults (teachers and parents) to provide a variety of opportunities and optimal levels of learning activities for struggling students so that they can be successful in gradually meeting challenging tasks.

\subsection{Rationale for the study}

The rising trend in the use of English as the medium of instruction in Saudi Arabia has spurred the growth of international schools, two of which being the schools in the current study. English, as EFL, is the medium of 
instruction in all the lessons and other daily school activities at these schools. Also at these schools, especially at the primary stage, English literacy Development (ELD) instruction is a support program or intervention rather than a separate curriculum subject. Because students' language proficiency affects their achievement in all subjects, teachers are in bad need to incorporate appropriate ELD approaches and strategies into all areas of the curriculum. To better understand the rationale for this study, it is important to look at the international schools' background in Saudi Arabia. Jawahir International Schools, as examples of these schools, are three international elementary schools with approximately 980 students. Two thirds of these students are foreigners (Philippines, Indians, Pakistanian) the rest are Saudis, Syrians and Egyptians. At these schools, classroom teachers were concerned about the lack of third grade students' progress reflected by the low test scores on standardized literacy tests, especially in reading and writing. The number of struggling readers and writers is increasing. Teachers were frustrated by the fragmented and limited amount of time spent each day on developing these skills. Moreover, research suggests that students with diverse cultural and linguistic background are at a higher risk of lower achievement on widescale measures, and of becoming school drop-outs (Kong \& Pearson, 2003).

Results of the pilot study, classroom observations (9 lessons), interviews with teachers and students ( 6 teachers and 15 students), conducted by the researcher, indicated that: 
- EFL literacy instruction has tended to focus on linguistic forms, e.g. phonics, word recognition, through memorization rather than constructing meaning through complex thinking and critical response,

- Teachers do not spend enough time explicitly teaching students to learn comprehension strategies and practice them independently. On average, teachers allocated 10\%, approximately 18 minutes, of their 3-hour literacy teaching to comprehension instruction,

- Teachers relied heavily on asking students questions before, during, and after reading. Very little instruction was focused on cognitive strategies or instruction to support students' acquisition of knowledge related to narrative or expository text structures,

- Overall, $88 \%$ of teachers provided at least one instructional event that was coded as comprehension instruction,

- When new skills were introduced, students did not receive enough teacher-guided or independent practice opportunities to ensure maintenance or transfer of the skills,

- Struggling readers were observed easily distracted and avoiding group work which was mainly centered on reading assigned text and answering comprehension questions. They demonstrated a lack of cooperation with their group members,

- teachers intentionally trivialized struggling readers and writers for the purpose of controlling other students and ending their lessons on time,

All these factors apparently left the struggling readers and writers with very little motivation and self-efficacy. Thus the idea of mediated cognitive strategies instruction through gradual release of responsibility model and parents involvement was easily combined with the schools principal's and

\section{8}


staff's desire to implement a team approach based program using the format of Readers'/Writers' remedial sessions in order to help students develop literacy skills, mainly reading and writing, and self efficacy belief.

\subsection{Statement of the problem}

The research problem of the present study could be summarized in the following statement:

There is a remarkable percentage of struggling readers and writers at primary stage at some international schools in Riyadh, that leads to their failure repeatedly and impacts passively on their motivation to study.

\subsection{Research Questions}

Therefore, the present study attempted to answer the following main question:

1. What is the effect of a suggested program based on mediated cognitive strategies instruction (MCSI) and parents' involvement when using culturally relevant high-interest texts on developing the literacy skills and self-efficacy of third grade struggling students?

The main question can be translated into the following sub questions:-

A. What are the "modified cognitive strategies?" "What does literature say about strategy instruction and parents' involvement in their children's learning?"

B. What are the English language literacy skills that grade three students' struggle with?

C. What are the features and principles of the proposed program based on mediated cognitive strategies instruction (MCSI) and parents' involvement to develop English literacy skills of third grade students at international schools? 
D. What is the effect of the suggested program on improving the targeted English literacy skills?

E. What is the effect of the suggested program on the treatment group self-efficacy belief?

F. Is there any relationship between students' self-efficacy belief and literacy skills development?

G. How do the participated teachers, parents and students value the mediated cognitive strategies practices that differ from traditional instructional procedures?

\subsection{Hypotheses of the study}

1. There is a statistically significant difference between the mean scores of the treatment group subjects on the pre- and post- administrations of the literacy tests in total score of the test as well as in each section (reading and writing) in favor of the post- testing scores.

2. There is a statistically significant difference between the mean scores of the treatment group subjects on the pre and post applications of the reading and writing self-efficacy scale in the total score as well as in each part (reading and writing) in favor of the post- application.

3. There is a relationship between students' reading and writing selfefficacy belief and literacy skills development

4. Most of the treatment group subjects from parents and teachers are satisfied with the proposed training program as measured by a semistructure interview conducted with teachers and parents individually at the end of the intervention

\subsection{Purpose of the study}

The purpose of this study is four-fold: 
- Identifying the English language literacy skills that grade three international school students struggle with.

- Identifying appropriate mediated cognitive strategies (MCS) for designing a program based on strategy instruction approach and parents involvement to improve the reading comprehension and writing skills of third grade international school students.

- Constructing a proposed program based on mediated cognitive strategies instruction and parents' involvement to develop English literacy skills of third grade struggling readers and writers.

- Measuring the effect of the proposed program on improving the English literacy skills and self-efficacy of third grade struggling readers and writers.

\subsection{Delimitations of the study}

The present study is delimited to:

- A sample of third grade struggling readers and writers selected from two international schools in Riyadh.

- Some reading and writing skills. The reading skills included: identifying the main idea, identifying supporting details, Identifying organizational patterns (explicit cause-effect relationship), guessing the meaning of unfamiliar words, making inferences and summarization. The writing skills included: Presenting a Clear, logical, well developed content, Sticking to the main idea, Supporting the main idea with details, Using a range of vocabulary, Writing a concluding sentence that summarizes the main idea, Applying grammatical rules correctly, and Applying writing mechanics correctly 
- A limited duration for implementing the proposed program (three months).

\subsection{Significance of the Study}

- Determining the effect of mediating cognitive strategies instruction on literacy skills of primary school struggling students.

- Providing EFL teachers, supervisors and curricula designers with first, a list of reading and writing skills that third grade students struggle with. Second, a list of culturally relevant high-interest texts appropriate for third grade struggling students at international schools.

- Providing a range of opportunities for working families to become more fully engaged in their children's learning experiences.

- Giving students more opportunities to practice cognitive strategies in and after school English classes.

- Exploring some of the ways in which teachers and parents can support their children's self efficacy.

\subsection{Definition of Key Terms}

The following terms have been identified for this study:

Struggling reader/writer: In the current study, a struggling reader/writer was defined as a third-grade reader and writer who had no identified learning disability but who was experiencing difficulty in the reading and writing process based on his or her performance on the developmental literacy assessment as well as teacher observations.

Cognitive Strategy Instruction: Gajria et al., (2007, p. 216) defined Cognitive strategies in Reading Comprehension as "cognitive processes that the learner intentionally performs to influence learning and cognition" 
Gradual Release of Responsibility — in the current study Gradual release of responsibility is defined as a teaching/learning model through which the responsibility of understanding reading cognitive strategies and using them in comprehending various culturally relevant and high interest texts is gradually released from teachers and parents to third grade struggling readers and writers.

Students reading and writing self-efficacy — In the current study the term "reading and writing self-efficacy" is used to refer to third grade international elementary school students' judgments of their capability to read a text and answer related comprehension questions as well as accomplish a well-structured writing task at designated levels.

\section{Review of Related Literature}

\subsection{Cognitive strategies instruction and Guided Practice in Literacy} Development

\subsubsection{Cognitive strategy based instruction}

Strategy-based instruction refers to the instructional methods teachers employ for supporting deep and interactive engagement with content, scaffolding students to meet with expected success, and developing selfknowledge as- learner. Cognitive strategy instruction primarily emerged from research that investigated the reading behaviors of proficient readers and how they successfully read and comprehend written texts (Block \& Pressley, 2002; Pressley, 2006). Donohoo $(2010,7)$ stated that it is an instructional approach that foreground the teaching of a small set of research-based strategies within the context of collaborative text discussions where responsibility for using strategies to construct meaning is shared among all group members. Also, it is a flexible framework; that can 
be introduced in various forms: in whole-class, small group or one-on-one formats and can be practiced in teacher-guided or student-managed settings. Donohoo $(2010,7)$ added that mediated cognitive strategies instruction can improve student comprehension and can be applied to different text types. Brown (2008, 539) highlighted four essential components of strategy instruction: (1) the teaching of comprehension strategies,(2) the shifting of strategy use from teacher to student,(3) the valuing of group learning, and (4) the lively sharing of ideas (see Figure 1).

Figure 1. Conceptual Image of a Strategy-Based Instructional Model

Source: Donohoo $(2010,7)$

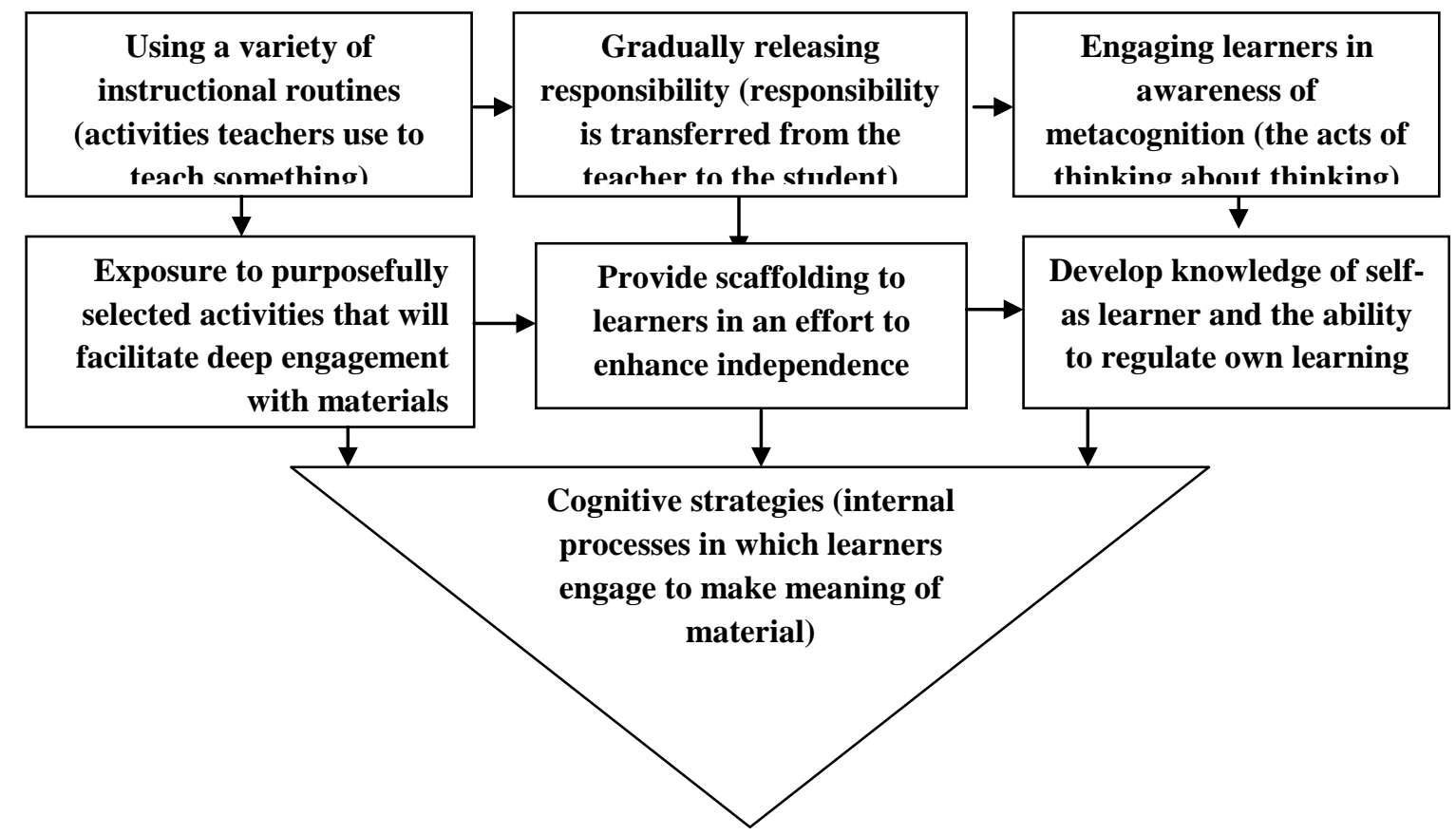

Marzano, Pickering and Pollock (2001) reviewed 42 cognitive strategy based researches and listed groups of strategies that have the most effect on reading comprehension across a wide range of student ability levels and ages. They reached that text structure, summarization, graphic organizers, 
question generating, and cooperative learning are among the strategies that yielded the highest gains for reading comprehension performance.

\subsubsection{The 'Five Mediated Cognitive Strategies' (5MCS)}

The 5MCS is a cognitive varied strategy-based interference for accelerating the reading comprehension skills of struggling readers; incorporating five strategies: a) predicting, b) questioning, c) investigating for meaning, d) schematic visualizing, and e) summarizing main ideas. Klingner \& Vaughn, (1996) pointed out that the main assumption the 5MCS model is based on is that humans' cognitive development happen when abstract concepts, first learned through social interactions then become internalized and made one's own. Guthrie et al., (2004) added that through the 5MCS, students are supposed to be actively engaged in the process of comprehending the reading texts, with the teacher and students' peers mediating their construction of knowledge. Following is a brief note of each strategy:

- Predicting strategy: represents what will happen next in the text based on what is known or with inference drawn from the author's ideas, or illustrations and visual clues that are created exclusively to lead the reader throughout the text. Prediction catalyzes other cognitive strategies, such as, activating background knowledge, previewing and over viewing or summarizing the content.

- Questioning strategy: using questioning strategy, the readers gets engaged in processing and identifying the information presented in the text they read and analyze its significance to generate questions which they can answer themselves. Oczkus (2003) assured that engaging readers in questioning strategy while reading has a leading benefit of 
cognitive flexibility since students can learn to form questions at different levels.

- Investigating for meaning. This strategy meets students' need to read and understand abstract facts in school subjects, e.g. science, mathematics, and social studies (Gajria et al., 2007; Lederer, 2000). Thus, the need to constantly extend knowledge about new concepts and vocabulary is fundamental for students, especially for struggling students, who already have made several failing attempts trying to comprehend learning content (Guthrie \& Davis, 2003).

- Schematic visualizing: The use of schematic visualizing alarm students' comprehension to the organization of the text and to the relationship between the various concepts and ideas described in the text. Schematic visualizing helps students in comprehending the text, as well as in memorizing facts, and analyzing information. Further, schematic visualizing, as visual representations, supports students who have limited vocabulary knowledge, as they act as mental images in simplifying complex concepts and describe them in less words (Zayyad, 2009).

- Summarizing: Pressley (2006) declared that the idea behind summarization is the supposition that humans do not recall everything they come across. Duke and Pearson (2002) added that instruction and practice in summarizing main ideas embedded in a text does not only improve student's ability to summarize, but also it improves their comprehension thoroughly.

Zayyad (2010) assured that the five cognitive strategies can be initiated in any given order, especially once all students become confident and independent in using them without the need for the teacher's intervention. 
However, for research purposes, the 5MCS can be delivered according to certain sequence. Later, the teacher can explain to the students that these strategies could be used entirely or partially as needed based on the reading demand and text complexity.

For the purpose of the current study the researcher followed the following order in modeling the strategies: 1) predicting, 2) questioning, 3) investigating for meaning, 4) schematic visualizing, and 5) summarizing the main ideas.

Gersten et al. (2001) organized all studies that evaluated multiple comprehension strategies into two sets: the ones that used two strategies that combine summarization and self-monitoring, and the ones that were conducted on more than two strategies. The researchers reported that results of the studies on the use of simultaneous multiple strategies echoed single-strategy studies on the importance of providing continuous feedback and sufficient modeling for students. One distinctive feature that is unique to multiple strategy instruction, when compared to single strategy model, is the ability of multiple strategy interventions to transfer skills to more generalized measures of reading.

Brown's (2008) Research has shown that good readers use multiple strategies when reading. Pressley (2002) is of the view that in keeping with that premise, teachers help students coordinate their use of several strategies right from the start instead of introducing individual strategies to them one at a time. Although teachers might target a specific strategy in a given lesson, teachers constantly remind students that good readers use many strategies to make sense of what they read. Also, Zayyad's research results (2010) pointed out that although teachers sometimes introduce the 
Cognitive strategies one by one, students quickly learn to coordinate their use-just as good readers do. Cognitive Strategies are not taught or practiced in isolation, but rather they are practiced within the context of real reading events, and blended into meaning-oriented text discussions. Teacher initially contributes more than students do to these discussionsexplaining and demonstrating strategic reasoning - then he or she transfers responsibility for strategy use as quickly as possible to students. This process of incrementally shifting control of strategic thinking from teachers to students is known as the Gradual Release of Responsibility Model. As the teacher phases out responsibility, students begin to model and scaffold effective use of strategies for one another.

\subsubsection{The Gradual Release of Responsibility (GRR) model and} Cognitive strategy instruction

Pearson and Dole (1987) surveyed successful comprehension strategy instruction and reached common components of mediated explicit teaching of strategies using the following sequence: (a) teacher modeling, (b) guided practice, (c) consolidation, (d) independent practice, and (e) application. Accordingly, Pearson and Dole (1987) developed a schema model illustrating the gradual release of responsibility from teachers to students.

The Gradual Release of Responsibility (GRR) is an instructional model developed by Pearson and Gallagher (1993). The GRR model of instruction proposes that the cognitive load should move slowly and purposefully from teacher-as-model, to collective responsibility, to independent practice and implementation by the learner (Duke \& Carlisle, 2011; cited in Donaldson (2011,6-7). The GRR is recognized as an effective approach for moving 
classroom teaching from teacher-centered, whole- group delivery to student-centered collaboration and independent practice. Sometimes referred to as "I do it, we do it, you do it," this model proposes a plan for providing scaffolded teaching that includes explanation, presentation, prompt, and practice.

The gradual release of responsibility model is the intersection of several theories, including the following:

-Piaget's (1952) focus on cognitive structures and schema theory;

-Vygotsky's $(1962,1978)$ focus on zones of proximal development (ZPD)

-Bandura's (1965) focus on attention, retention, reproduction, and motivation; and

-Wood, Bruner, and Ross's (1976) focus on scaffolded instruction.

All these theories stress that learning originally takes place through interactions with others, and when these interactions are intentional, specific learning occurs. Frey and Fisher (2006) pointed out that most current implementation efforts of the gradual release of responsibility model, unfortunately, limit these interactions to adult and child exchanges lacking a vital component: learning through collaboration with peers. Figure (2) shows the four interactive/ interrelated components of the gradual release of responsibility model (including: focus lessons, guided instruction, collaborative learning, and independent tasks).

Figure (2) Components of the Gradual Release of Responsibility Model

Source: Retrieved from www.literacyleader.com 


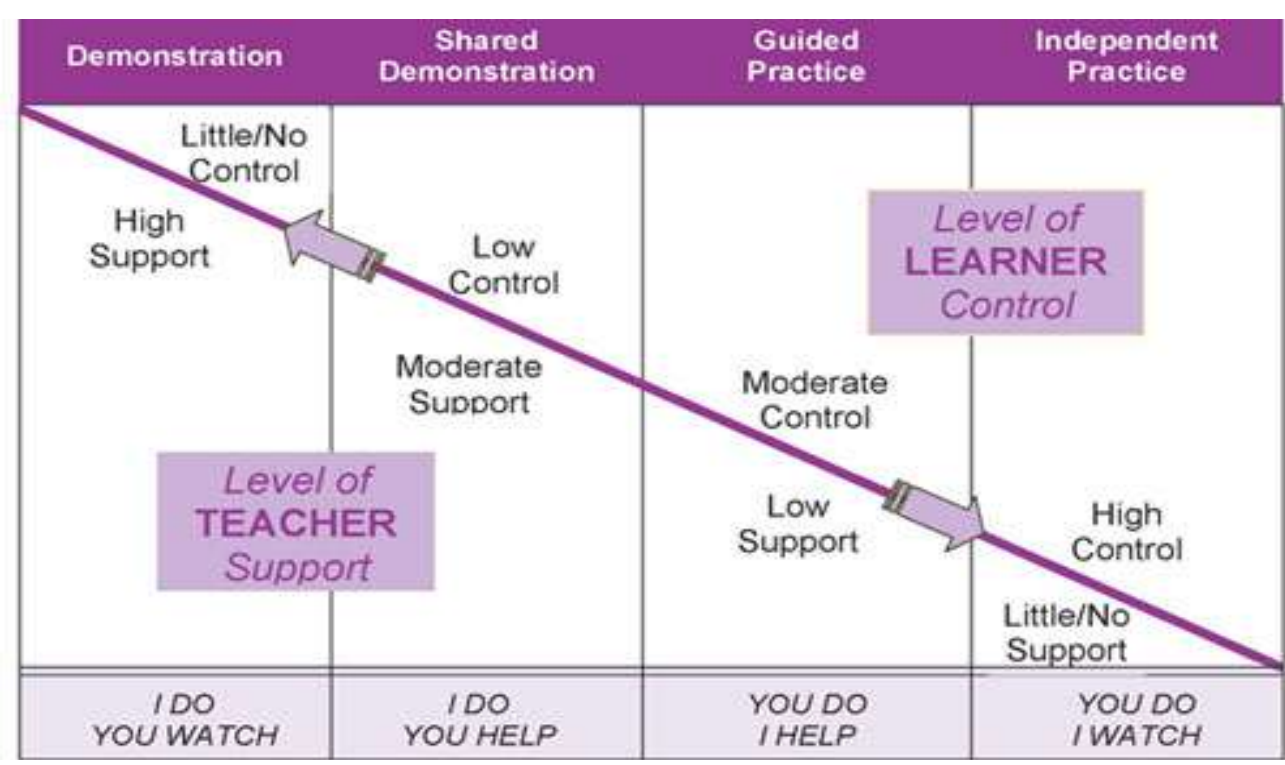

Fisher and Frey (2013) indicated that all four phases of the gradual release of responsibility framework - focused instruction, guided instruction, collaborative learning, and independent learning — are necessary if teachers want students to learn deeply, think critically and creatively, and be able to mobilize learning strategies. They added that the model is not linear; teachers can reorder the phases-for example, begin a lesson with an independent task, such as a quick-write, or engage students in collaborative peer inquiry prior to providing teacher modeling. They stressed that "What is important and necessary for deep learning is that students experience all four phases of learning when encountering new content".

\subsubsection{The Gradual Release of Responsibility Instructional Framework} and Cognitive Strategies Instruction

- Focus Lessons/ the modeling phase (I Do). throughout this phase teachers/adult model, through a think-aloud, their own metacognitive processes as active readers through supplying students with information about the strategies needed to understand a text, or specific segment of a text. This phase is almost always done as whole class activity; its aim is 
to clearly establish purpose and to ensure that students have a model from which to work.

- Guided Instruction (we do). In this phase responsibility for learning is being shifted from knowledgeable others (teachers, peers, parents) to students. During guided instruction, teachers prompt, question, facilitate, or lead students while practicing certain cognitive strategy/ies that help them increase understanding of a particular text. This phase occurs in small, purposeful groups. Tomlinson (2001) declared that Guided instruction is an ideal time for teachers to differentiate: content, process, and product.

- Collaborative Learning (you do it together). Students during this phase consolidate their thinking and understanding of strategies they learned during the previous two phases through Collaborative learning opportunities, negotiating with peers, discussing ideas and information, or engaging in inquiry with others. For example, students in groups of four read a segment of a text in common, taking notes, and then discuss the text using predicting, questioning, summarizing, and clarifying. During text discussion, students take notes. At the end of the discussion, each student is asked to summarize the reading individually.

- Independent Learning (you do it alone). This phase addresses the most important goal of effective instruction - providing students with practice opportunities to applying learned strategies in completing independent tasks. In this phase, students transfer learned cognitive reading strategies to new texts. As students transfer their learning to subordinate tasks, they become active readers and capable learners. 


\subsection{Parental involvement}

Ball, (2006) assured that active family involvement results in better social, behavioral, and academic results for students from all ethnic and economic backgrounds. Wanders, Mendez, \& Downer (2007) added that family involvement in their children's education is critical especially for struggling/at risk students. Decker, Decker, \& Brown (2007) declare that there is no one single set of practices that define a family-school partnership.

\subsubsection{Framework for Accessible parents Involvement}

Epstein's (2001) presented a comprehensive perspective framework on family involvement, which based on review of studies from preschool through high school that included educators and families. Epstein's (2001, 17) framework comprises six types of family involvement as follows:

1. Parenting - home environments that consolidate achievement

2. Communicating - two-way information sharing between school and parents

3. Volunteering - helping with planned activities in and outside the classroom

4. Learning at home-parents assisting children in the learning process at home

5. Decision making - parent involvement in school decisions

6. Collaborating with the community - use of local services and resources to help children learn.

Morrison, Storey and Zhang $(2011,23)$ declared that effective teachers should use aspects from all elements of this model, selecting strategies that motivate and enable family members and any other person get involved in 
supporting their children's learning. Parent involvement model presented in the current study bases on Epstein's research-based work, grouped into two components: first, staff and parents Communication e.g., Family-teacher dialogue-journals and interviews. Second, family-child collaborations: Family learning opportunities that build on classroom learning experiences.

\subsubsection{Parental involvement and English literacy development}

Morrison, Storey and Zhang $(2011,21)$ assured that no need for parents to be proficient in English in order to help their child. They add that "when parents continue to support the development of the first language, the child's underlying knowledge, conceptual base, and language ability are improved. This cognitive and linguistic knowledge is transferable and helps the student while learning English".

Huang (2013) proposed a model of parental involvement and engagement in the literacy domain through merging Vygotsky's concept of scaffolding and Epstein's frameworks, as shown in Figure 3.

Figure 3. Parental involvement in literacy learning and development Source: Huang $(2013,253)$

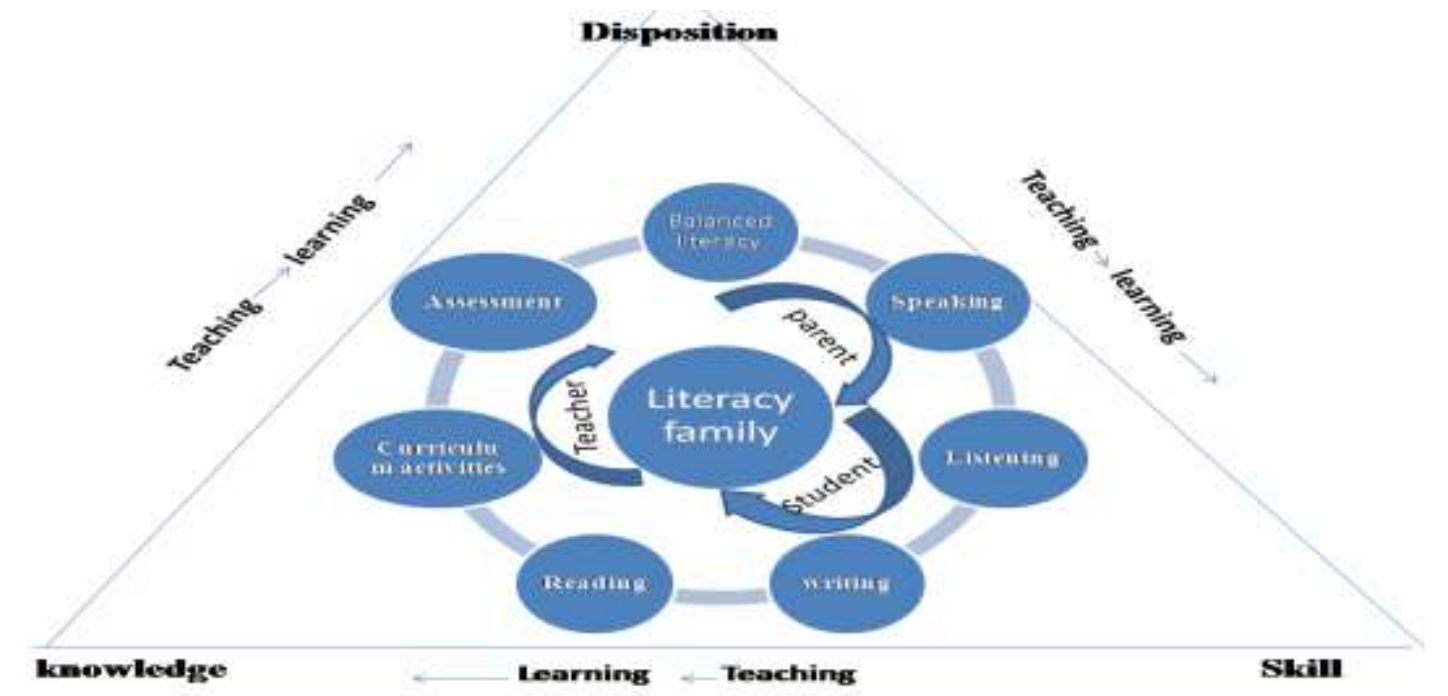


This model illustrates disposition, knowledge, and skill as the essential basis of literacy development of a student. Teaching-learning, presented as a continual relationship, follows together with the three major basis of literacy development outside of the triangle. Teachers, parents and students are the center of the literacy family inside of the triangle (knowledgedisposition-skill). There are nine main elements of literacy (curriculum, subject matter, new literacy, speaking, listening, writing, reading, assessment, and activities) within the literacy family.

\subsection{Self efficacy and Development of English Literacy}

According to Bandura (1997); Individuals, generally act on their self-belief based on their previous performances in certain tasks. Thus success nourishes their positive self-efficacy, while, failure lower their selfefficacy. Cole $(2002,328)$ declared that students with positive selfefficacies, opposite to learners with passive self-efficacies, have a strong sense of control over their learning and believe that they have the potentials to succeed. Therefore, Cole recommended that teachers should pay much attention to assess students' self-efficacies and provide meaningful, motivational activities that will improve and enhance students' self efficacy (2002, 328). Pajares (2006, 355) argued that identifying, challenging and altering low self-efficacy early is essential to students' success and adaptive functioning as teachers can help students to develop a better understanding of their potential.

Gong, Zhang, Kiss and Ang-Tay $(2011,5)$ suggested that certain learner variables such as self-efficacy, motivation, and effort can play an essential role in literacy learning. Nicolaidou $(2010,17)$ referring to writing selfefficacy in particular, stated that self-efficacy beliefs have a predictive and 
meditational role on writing performance. Self-efficacy also impacts the learner's performance in reading by affecting the student's choice of activities, task evasion; effort put forward in task, and aim insistence. The National Institute for Literacy (2007) confirmed that individual's aims, values, and beliefs regarding the reading topics, processes, and outcomes affect their motivations for reading, which involves self-efficacy. Zimerman (2000), in agreement with Bandura's argument, believed that self-efficacy is not a static permanent belief about failure. It is rather a taskspecific set of beliefs from frequent failing experiences in the past. Thus, it can be treated by: a) providing psychologically safe learning environments, b) making informed curriculum decisions, and c) applying instructional methods that foster success. In the current study, students were taught in a safe educational environment, where they received continuous support and encouragement not only from the teacher, and their own peers in their groups but also from their parents. The social setting which was an integral part of the GRR model provided students with a sense of belonging and support.

\section{Methodology}

\section{Design of the study}

The current tendency in social sciences research encourages the use of multiple methods to capture humans' phenomena from different perspectives (Creswell, 2003). Accordingly, the current study utilized: first, the pretest-posttest experimental group design. The independent variables were the use of the mediated cognitive strategies (through GRR model) and parents' involvement. The dependent variables were: students' literacy skills (reading and writing) and self- efficacy belief. Second, because this 
study was heavily dependent on the use of socially constructed collaboration work among teachers, parents and peers of students, it is methodologically eclectic, making use of qualitative measures (participants' observation and focus interviews) as well as quantitative measures to assess students' literacy development.

\section{Setting and participants}

Two English teachers, two science teachers, two math teachers, who are the main teachers for the participating classrooms, 25 third-grade struggling students aged 8-9 years old (from two typical primary international schools; 12 in the first school and 13 in the second school) and their parents, participated in the study. All students spoke English as a foreign language, their nationality is different (Egyptian, Saudian, Indian, Pakistani) accordingly, their mother tongue is different (Arabic, Indian and Urdu). In each school, teachers met regularly with these and their other students in homogeneous, guided reading and writing groups. Among students, 14 (or $44.4 \%$ ) were boys and 11 (or 55.6\%) were girls.

The participating schools were two international elementary schools in Riyadh in Saudi Arabia (First and Second Jawahir AlRiyadh International Schools). Each school has four third-grade classes (two for boys and two for girls), and each class has approximately 20 students. Classes were held from Sunday through Thursday, typically from 6:45 am though 12:30pm.

\section{Instruments}

- The literacy skills checklist: The checklist included thirteen sub- skills (6 reading and 7 writing sub-skills). The reading sub-skills included: identifying the main idea, identifying supporting details, Identifying organizational patterns (explicit cause-effect relationship), guessing the 
meaning of unfamiliar words, making inferences and summarization. The writing sub-skills included: Presenting a Clear, logical, well developed content, Sticking to the main idea, Supporting the main idea with details, Using a range of vocabulary, Writing a concluding sentence that summarizes the main idea, Applying grammatical rules correctly, and Applying writing mechanics correctly. It was submitted to a panel of jury members, specialized in the field of curriculum and methods of teaching English, who indicated that the checklist was valid and the skills included were clear and adequate. (See appendix 1)

\section{The data collection included the following measures:}

\section{Reading and writing pre-post Tests:}

Aim: One was used as a pre-test and an equivalent test was used as a posttest. Students' performance in reading comprehension and writing was pretested to establish a baseline measure, and post-tested to measure improvement in the literacy performance (reading and writing skills).

Content: The two tests consisted of two sections: in the first section students are asked to read a text and answer related questions. The text is followed by two question types: MCQ (5 items), and $3 \mathrm{WH}$ questions that require brief written response. In the second section, students are asked to look at a given picture and write 6-8 lines describing what is happening in the picture in their own words. In the light of the results of the test pilot study, the time allowed for each test is forty five minutes. Two modes were utilized to evaluate students' written answers during the pre-post tests: holistic scoring, in which students' written answer for the three WH questions was evaluated as a whole by two raters out of 3 for each question, and analytical scoring for the writing question in the second section of the 
test, which was done by two raters based on a scoring rubric of the necessary writing skills. The tests are scored out of thirty five scores for each test.

To validate the test, the first version was given to 8 TEFL specialists and 4 native EFL teachers to evaluate it in terms of content appropriateness, number of items and suitability of the test to the students' level. To validate the test, the first version was given to 8 TEFL specialists and 4 native EFL teachers to evaluate it in terms of content appropriateness, number of items and suitability of the test to the students' level. In addition to content validity, the researcher estimated the test intrinsic validity using the following formula.

Intrinsic Validity $=$ reliability coefficient $=0.88$. This value is considered high for the test validity.

To establish the test reliability, the test-retest method was employed with an interval of two weeks. The reliability coefficient was 0.79 , which is judged to be relatively high.

\section{Reading and writing self -efficacy Scale (modified by the researcher)}

Aim: to assess improvement in the participants' efficacy beliefs in reading and writing.

Content: This scale was divided into two parts; the first part consisted of ten items and used to measure students' reading self-efficacy. This part of the scale based on these three related questionnaires: 1) Morgan-Links Student Efficacy Scale (MLSES) constructed by Jinks and Morgan (1999); 2) reading self-efficacy scale designed by Piercey (2013); and the reader self-perception scale designed by Henk and Melnick (1995). The second part of the scale consisted of ten items to assess students' writing self-

\section{8}


efficacy. It was extracted from Pajares and Valiante's (1997) writing skills self-efficacy scale, and Pajares et al., 2001. Though the self efficacy scale based on previously used measures, but in this study new items were added and existing items were rewritten to suit students' language level and a focus on reading and writing skills. The scale followed a five-point Likert Scale that adopts a rubric ranges from (1) to $(5)$. $(1=$ very unconfident, $5=$ very confident). It is worth noting that items $3,7,14$ and 18 were negative items. The pupils' score on this scale might range from 20 (the minimal score) to 100 (the maximal score).

To validate the scale, a first version was given to TEFL and educational specialists to make sure that the scale actually measured what it claimed to measure and hence some items were modified. Then, the first form of the scale was administered to sample of 15 third grade struggling students (other than the research sample) to determine its duration and reliability. It was proved that 30 minutes would provide ample time for students to cover all the items. The Alpha Cronbach's reliability coefficient of the two parts of the scale was (0.85). The scale validity coefficient among items was between $0.45-0.68$, which indicates a high level of internal consistency and reliability.

3. A semi-structure interview was conduct with teachers and parents individually at the end of the intervention. The interviews focused on their value of the 5MCS, GRR and its impact on students' reading and writing performance as well as self-efficacy during the intervention.

4. Moreover, the collected data included direct classroom observations by the researcher and samples of students' daily work. 


\section{The suggested program}

The following is a description of the steps the researcher went through to design the current program:

\section{Key Program Features and principals}

- A school-wide commitment to improve students' literacy skills, through implementing a co-teaching model using the format of Readers'/Writers' remedial sessions,

- Whole-school planning to systematically address students' identified literacy needs through whole-class, small group and individualized instruction,

- Systematic collection and analysis of evidence of students' development reading and writing acquisition,

- $\quad$ Explicit teaching using a range of cognitive instructional strategies based on students' needs, targeting groups and individuals for specific and relevant instruction,

- Established routines, activities, patterns of classroom organization and instructional model (gradual release of responsibility, GRR) that is known to support effective literacy learning,

- $\quad$ Ongoing assessment, monitoring and reporting of student's progress,

- $\quad$ Systematic reviewing, adjusting and re-planning to facilitate further progress,

- Valuing and broadening students' linguistic and cultural repertoire,

- Students' home Language and culture are recognized, valued and used in the learning of English literacy,

A two-way approach to teaching and learning is embedded; there is on-going hands-on collaboration activities, and 
High but realistic expectations for all learners, ensuring that there is accuracy in all Literacy Sessions.

\section{Aim of the program:}

This program aims at enhancing the literacy skills (reading and writing) of the third grade struggling students at international schools in Saudi Arabia via using mediated cognitive strategies (MCS), gradual release of responsibility (GRR) model and parents involvement.

\section{Learning objectives of the program}

By the end of the program, students should be able to:

First, in reading:

- identify the main idea of a text,

- identify specific stated details in a text,

- Identify organizational patterns (explicit cause-effect relationship),

- make inferences about the topic of the reading text, and

- Using contextual clues effectively to figure out the meaning of an unfamiliar word

- Extracting salient points to summarize a text

Second, in writing:

Write a well-developed piece of writing through

- Presenting a Clear, logical, well developed content,

- Sticking to the main idea

- Supporting the main idea with details

- Using a range of vocabulary

- Writing a concluding sentence that summarizes the main idea

- Applying grammatical rules and writing mechanics correctly 


\section{Duration of the program:}

The program started in the first term of the school year 2014/2015. Two class periods (in each school) were held for training teachers and parents on using mediated cognitive strategies (MCS), through the GRR model, in English literacy development (LED) lessons for grade three struggling readers and writers. After that, the trained teachers and parents carried out the program assigned activities with the students through using the MCS and GRR model. The program was implemented in two locations: at school (two class periods per-week) and at home with parents (two hours per week) over a period of twelve weeks (three months). Students received 52 sessions in total as follow: (a) 2 sessions for the pretest and posttest conditions (45 minutes each); (b) two 45-minute sessions of strategy training at school; (c) 24 45-minute sessions of MCS implementation; and (d) 24 hours (two hours per-week) student-parent guided practice.

\section{Content of the program}

The program consisted of two stages:

\section{First, Teacher's and parents' Training in the MCS intervention}

For the purpose of providing a model for the teachers and parents, the first implementation of the MCS, following the phases of the GRR model, with students was conducted by the researcher with the teachers and parents participating as both observers and "co-teachers" following Friend and Bursuck's (2006) “one lead, one assist" model of co-teaching. Upon completing the training lessons, the teachers and parents took over and gradually handed over the leading roles of all activities to students. The teachers of both schools were able to explicitly train for at least two consecutive sessions. In addition, a one-to-one conversation was conducted 
with each of the teachers and parents prior to engaging in the MCS intervention and how this intervention might affect students' literacy skills, engagement and self efficacy. Further, teachers received ongoing biweekly feedback on their work on the MCS, the GRR model and guidance on how to follow up with all students individually and in small groups.

\section{Second, the school based and home based intervention}

The content of the program is activity-based. The content was selected and organized in the form of School based remedial sessions suitable to the students' level supported by home based activities to be completed at home with parents' guidance. The program includes 24- 40 minutes sessions at school; in addition, two hours weekly were assigned to parent-student guided activities. Reading and writing skills were integrated together around a thematic training session. Each session has its own objectives, materials and activities.

\section{Program delivery (Procedures)}

The program devotes two (40 minutes) sessions of two school days to reading and writing activities in addition to regular instruction in EFL. These 40-minute class periods are dedicated to celebrating the joy of reading and writing. Teachers mediated the learning process of all students in the classroom by taking part in the following activities. First, they explained to all students the purpose and importance of engaging in these cognitive strategies and demonstrating to them how such strategies affect literacy acquisition. Second, they demonstrated and modeled each of the MCS strategies separately, starting with prediction, followed by the questioning strategy which was combined with the previously learned strategy (prediction). Upon proceeding to all strategies the teacher ensured that each new strategy was introduced and practiced in conjunction with the previously taught 
strategies and so forth until all strategies were fully introduced and modeled by the teacher. Once the teacher modeled all MCS strategies and had provided students with multiple opportunities to practice each activity as needed based on the teacher's estimation, then students were encouraged to practice using the strategies on their own. The basic routine of a typical literacy intervention session followed the phases of the GRR model, represented in a whole-group mini-lesson, a large block of independent group work (students in groups played the following roles: the coach, the first reader, and the second reader), independent reading and discussion in pairs and small groups, followed by a whole-class share, and individual writing in response to teacher-provided prompts (open-ended questions designed to engage students in personal, critical, and creative responses to the topic of the reading text or a related picture).

\section{Materials}

1. The selected reading texts: For the purpose of this study, a set of 15 informative and narrative texts, in the form of high/interest texts at the instructional readability level of the students were selected from texts that cover an array of topics. The narrative and informative texts were alternated so that the students would be trained on seven narrative texts and eight informative texts throughout the intervention period. The selected texts included paragraphs at the third grade reading level. Texts were selected due to its lengthy paragraphs which allowed for sufficient practice on the paragraphs and because it included all elements of MCS: the anticipation of events, questioning the ideas and events in the paragraph, investigating the meaning of difficult or new words, learning of the compare contrast schema, and practice summarizing the main ideas that are embedded in the paragraph. Moreover, Close reading 
requires that students re-read the selected text a number of times. Subsequent readings of the text allow students to dig deeper into the meaning of the text, comparing the text with other texts and what they know or think. The narrative passages cover topics that are of interest and culturally related to students, including adventures and legends. The expository texts included scientific topics and 'Mysterious Wild Animals'.

\section{Writing prompts}

The daily writing prompts mediated students' learning of literary skills. The prompts consisted of open-ended questions grounded under topics such as "Me and the text, point of view, character map, and character development. Over the three months, students responded to a total of 20 writing prompts for the 15 texts they read.

3. Classroom environment has three centers; one for training and modeling in groups, one for independent reading and one for writing. Students rotate through the stations every 15 minutes for the entire class period.

4. Cueing Cards. Students received cueing cards for each of the 5MCS activities.

These cueing cards helped the students to smoothly switch between the activities and to move from one step to another.

5. Parents' literacy package or "toolkit." It contained a parent's guidebook (similar to lesson plans following the GRR model steps) along with related activities involving reading fluency, phonics, vocabulary, reading comprehension, and writing activities that should be completed by the student with parent guidance.

\section{5}




\section{Results and Discussion}

Analysis of data in the present study depended on quantitative and qualitative parts. The quantitative part depended on statistical analysis of students' scores on both pre-post application of the literacy (reading and writing) tests and the reading and writing self-efficacy scale. The qualitative part included description of teachers' and parents' perceptions about the value of mediated cognitive strategies instruction (MCSI) through the GRR model, and their usefulness in developing students' literacy skills and self-efficacy during the intervention. This analysis was based on semistructure interviews conducted with teachers and parents individually at the end of the intervention. Moreover, the collected data included direct classroom observations by the researcher and samples of students' daily work. The results are presented by relating them to the study hypotheses.

\subsection{First: Quantitative Data}

\section{a) The First Hypothesis}

To determine the relative extent of change fostered by the implementation of the proposed program from the pre- to the post-administration of the literacy tests for the treatment group, t-tests for paired samples (small groups) were used. The t-test aimed at comparing the mean scores of the treatment group on the pre-test and the post-test in literacy skills.

Table (1) t-test results comparing the pre-test vs. post-test means for the treatment group in literacy skills (reading and writing)

\begin{tabular}{|c|l|l|l|l|l|l|l|}
\hline $\begin{array}{c}\text { The reading \& } \\
\text { writing test }\end{array}$ & Application & N & M & SD & D.F. & $\begin{array}{l}\text { t. } \\
\text { value }\end{array}$ & $\begin{array}{l}\text { Sig } \\
\text { level }\end{array}$ \\
\cline { 1 - 6 } Reading section & Pre- & 25 & 4.16 & 1.14 & 24 & 40.72 & 0.001 \\
\cline { 2 - 6 } & Post- & & 13.48 & 0.65 & & & \\
\hline Writing section & Pre- & 25 & 7.00 & 1.29 & 24 & 40.04 & 0.001 \\
\hline
\end{tabular}




\begin{tabular}{|c|l|l|l|l|l|l|l|}
\hline $\begin{array}{l}\text { The reading \& } \\
\text { writing test }\end{array}$ & Application & N & M & SD & D.F. & $\begin{array}{l}\text { t. } \\
\text { value }\end{array}$ & $\begin{array}{l}\text { Sig } \\
\text { level }\end{array}$ \\
\hline \multirow{2}{*}{ Total score } & Post- & & 17.96 & 1.27 & & & \\
\cline { 2 - 7 } & Pre- & 25 & 11.04 & 1.90 & 24 & 56.58 & 0.001 \\
& Post- & & 31.44 & 1.56 & & & \\
\hline
\end{tabular}

Table (1) indicates that there is a statistically significant differences at 0.01 level between the mean scores of the treatment group on the pre-test and post-test in overall literacy test in favor of the post-test scores. Since the estimated $t$-value was $(t=56.58)$. Moreover, the $t$-test results proved that there were statistically significant differences between the pre-post tests mean scores of the treatment group in each section of the test (reading and writing since the " $\mathrm{t}$ " values were (40.72) for the reading section and (40.04) for the writing section. Thus the first hypothesis was confirmed. This result can be clarified in the following figure:

Figure1 The pre-test and post-test mean scores for the treatment group in literacy skills (reading and writing)

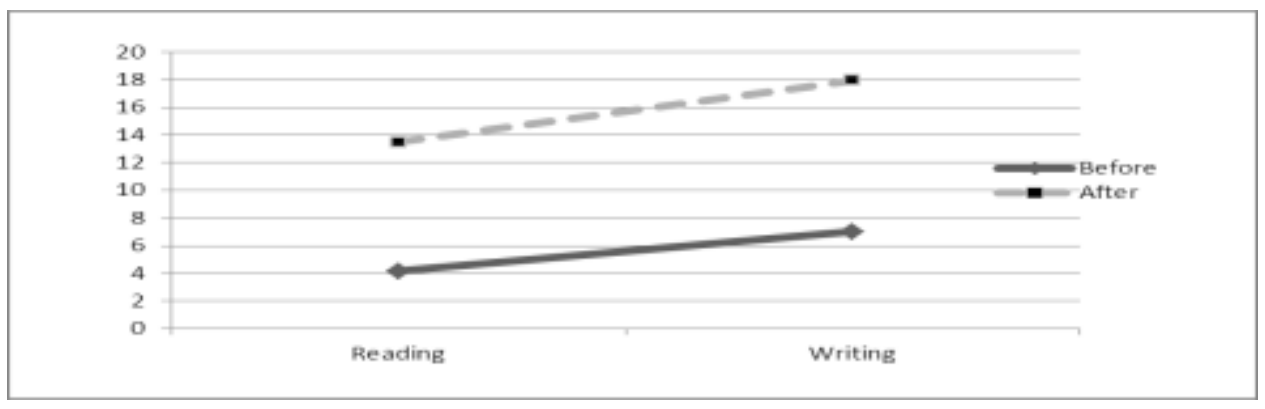

b) The Second Hypothesis

In order to verify the second hypothesis, The mean scores, std. deviation and ' $t$ ' test values of the treatment group subjects on the pre and post applications of the reading and writing self-efficacy scale were calculated. Results are shown in table (2). 
Table (2) Means, std. Deviation, and " $t$ " value of the treatment group subjects' scores on the self-efficacy scale

\begin{tabular}{|c|c|c|c|c|c|c|c|}
\hline Self efficacy scale & Application & $\mathbf{N}$ & $\mathbf{M}$ & SD & D.F & t. value & Sig level \\
\hline \multirow[t]{2}{*}{ Reading part } & Pre- & \multirow[t]{2}{*}{25} & 15.04 & 1.46 & \multirow[t]{2}{*}{24} & \multirow[t]{2}{*}{82.34} & \multirow[t]{2}{*}{0.001} \\
\hline & Post- & & 46.76 & 1.59 & & & \\
\hline \multirow[t]{2}{*}{ Writing part } & Pre- & \multirow[t]{2}{*}{25} & 16.08 & 1.35 & \multirow[t]{2}{*}{24} & \multirow[t]{2}{*}{81.37} & \multirow[t]{2}{*}{0.001} \\
\hline & Post- & & 43.76 & 2.24 & & & \\
\hline \multirow[t]{2}{*}{ Total score } & Pre- & \multirow[t]{2}{*}{25} & 31.12 & 2.52 & \multirow[t]{2}{*}{24} & \multirow[t]{2}{*}{36.33} & \multirow[t]{2}{*}{0.001} \\
\hline & Post- & & 88.88 & 8.99 & & & \\
\hline
\end{tabular}

Table (2) indicates that there is statistically significant difference at 0.01 level between the mean scores of the treatment group on the pre- and postapplications of the self-efficacy scale in total score in favor of the post-test scores. Since the estimated $t$-value was $(t=36.33)$. Moreover, the $t$-test results proved that there is a statistically significant difference at 0.01 level between the mean scores of the treatment group on the pre- and postapplications of the self-efficacy scale in each part of the scale (reading and writing) since the " $t$ " values were (82.34) for the reading part and (81.37) for the writing part. Therefore the second hypothesis was accepted. This result can be clarified in the following figure:

Figure2 The pre-test and post-test mean scores for the treatment group in self-efficacy (reading and writing)

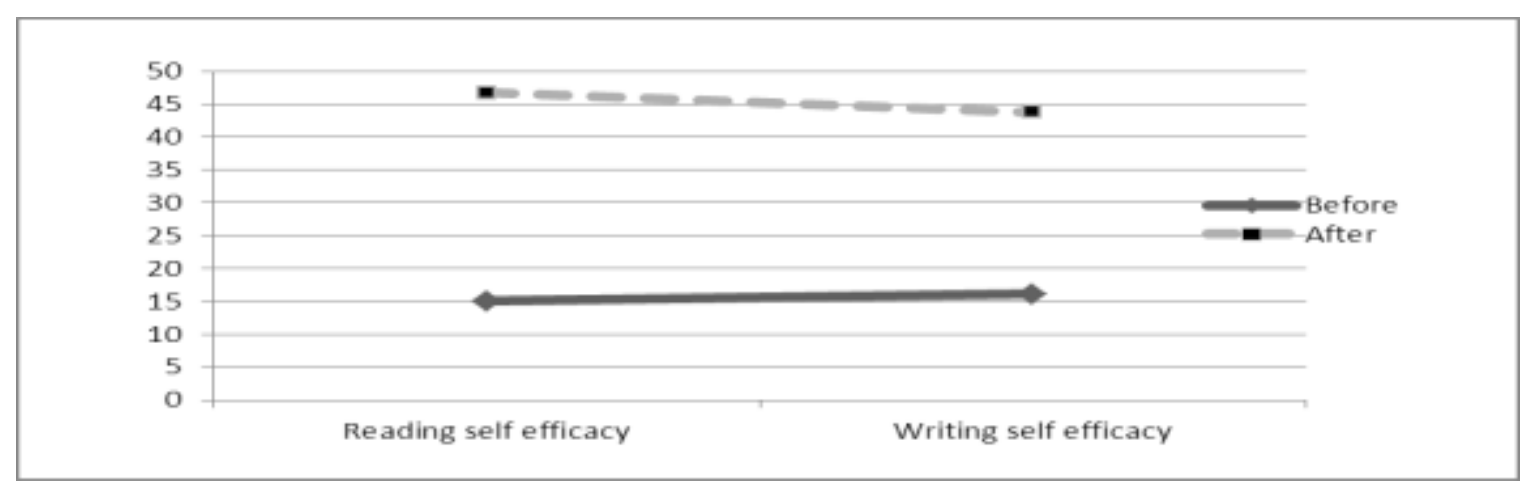


Moreover, the effect size of the independent variable (the proposed program) was calculated in its relation to the dependent variables (improving students' literacy skills and self-efficacy). This is shown in table (3) below.

Table (3) the effect size of the proposed program

\begin{tabular}{|c|c|c|c|c|c|c|c|}
\hline $\begin{array}{c}\text { The } \\
\text { independent }\end{array}$ & \multicolumn{2}{|c|}{ The dependent variables } & $\mathbf{T}$ & D.F & $\eta^{2}$ & $\begin{array}{c}\text { Effect } \\
\text { size }\end{array}$ & Judgment \\
\hline \multirow{6}{*}{$\begin{array}{l}\text { The proposed } \\
\text { program }\end{array}$} & \multirow{3}{*}{ Literacy skills } & Reading & 40.72 & 24 & 0.99 & 1.61 & Large \\
\hline & & writing & 40.04 & 24 & 0.99 & 1.30 & Large \\
\hline & & total & 56.58 & 24 & 0.99 & 1.43 & Large \\
\hline & \multirow[t]{3}{*}{ Self-efficacy } & Reading & 82.34 & 24 & 0.99 & 1.54 & Large \\
\hline & & writing & 81.37 & 24 & 0.99 & 1.37 & Large \\
\hline & & total & 36.33 & 24 & 0.98 & 1.41 & Large \\
\hline
\end{tabular}

Table (3) shows that the proposed program had a large effect size on the development of students' literacy skills, and self efficacy belief. But the improvement in students' performance varied from one section in the literacy test to another. This is clear because it ranged from the highest score (1.61) in the reading section followed by 1.30 in the writing section. Also, the effect size of the program on reading self efficacy was more than its effect size on writing self- efficacy. All these together verify the first and the second hypotheses set by the present study.

c) The Third Hypothesis

Investigating this hypothesis, correlation coefficient between the percentage of developed performance in literacy skills and self efficacy beliefs for students of the treatment group was calculated. See table (4).

Table 4 Correlations matrix between the developed performance of literacy skills and self efficacy beliefs for students of the treatment group 


\begin{tabular}{|c|r|r|r|}
\hline Variables & Reading & writing & Literacy \\
\hline Reading Self-efficacy & -.180 & .017 & .027 \\
\hline writing Self-efficacy & .000 & -.188 & -.224 \\
\hline literacy Self-efficacy & -.175 & -.137 & -.164 \\
\hline
\end{tabular}

Results in table (4) showed that correlation coefficient between the percentages of developed performance in literacy skills and self efficacy beliefs was -0.164 (not significant) according to Cohen (1988) who classified correlation coefficient $=(.10-.29)$ as a small effect, $(.30=.49)$ as a medium effect and (.50-1) as a large effect. Thus, hypothesis three was not verified as there was not a correlation between developing literacy skills and self-efficacy belief for the treatment group students.

\section{Qualitative data collection and analysis}

The research involved four qualitative data sources: the participating school teachers; weekly phone calls with the participating parents; classroom observational notes; and students' and parents' interviews.

At the end of the semester, students were interviewed; the researcher asked them questions regarding their self-efficacy in reading and writing: e.g. How confident are you in your abilities in reading/writing? How confident are you that you can learn to be good reader/writer? How well can you finish your reading/writing homework on time? Also, the participant teachers responded to an open-ended questionnaire regarding what they viewed as the strengths and weaknesses of the program. Then the researcher interviewed the parents individually. Specifically, the researcher asked questions regarding what they liked about the program, what they observed about the development of each student's literacy skills, what they found challenging, what they will continue to do in the future, and what 
they will do differently. The researcher also communicated with parents on the phone weekly in order to find out how they were doing with the program, and what they thought about the materials. Also, the researcher visited the class once a week and observed teachers while teaching the mini lessons or conduct group activities. In addition, the researcher observed how each student did activities within their groups and individually. Results of these assessments showed that the majority of participating students of struggling readers and writers made steady progress in reading and writing as well as self efficacy over the 12 weeks of the intervention.

Four major themes emerged from analyzing the qualitative data:

The first theme was termed resources, which included quality Parents' literacy package (with its culturally relevant high-interest texts and various worksheets). The literacy package increased opportunities for the parents to interact with their children during their reading time. Some parents indicated that 'The literacy packages gave us more opportunities to read with our kids.' Similarly, others noted, 'We spent more time reading and discussing culturally relevant texts together in our family.'

The second theme, instruction, encompassed many MCS remedial/training sessions at school and guided practice with classmates and with parents following the steps of the GRR model that revealed the overall structure of this program. Teachers identified a number of key points that were of relevance to the GRR model. Both EFL teachers identified structure, which includes organization and order, working in small group, and constructive feedback as one of the most influential factors in the program intervention. As students collaborated, the struggling readers observed how their more capable peers made use of strategies. They learned to rely not only upon 
their teacher but also upon one another. Also, teachers felt that the MCS influenced, not only how the students worked, but also impacted the teachers' instructional practice. The teachers stated that the MCS strategies brought new meaning to their teaching practice. They expressed their satisfaction with the way that the MCS activities were arranged and sequenced for the students.

These findings are consistent with that of Guthrie et al. (2004)) who assured that an instructional framework that merges motivational and cognitive strategy support in reading will increase engaged reading and reading comprehension. Supportive classroom context, according to Guthrie and Davis (2003) can be achieved by providing interesting materials that are connected to students' lived experiences, teacher's support and feedback, explicit instruction of important cognitive reading strategies, and fostering students' collaboration rather than competition.

Moreover, all parents indicated that MCS training and the steps of the GRR model were an effective resource to improve literacy skills. One of the parents, said, 'My daughter, Aida, felt more comfortable and confident when she reads for me trying to read aloud and to orally describing the cognitive strategy she is using, such way raised her competence in reading and learning English". Teachers made similar comments saying, 'it is important to give students an opportunity to reflect about the cognitive strategies they used, how it helped them, and why.'

The third theme, opportunity, included statements about the quality of the total time spent that involved reading and writing activities. The role of structure which included the organization and order of these activities, actively engaging students within small groups that require full 
collaboration among group members, interaction within the group members, and teacher's constructive feedback on students' performances.

Motivation emerged as the final theme. The theme of motivation was covered in many areas of the parents' interview data, phone communications, and field notes. The theme of motivation was incorporated in parents' statements saying they learned a great deal about their children's reading and writing interests, curiosity, learning attitudes, and language development. It also included statements about the role of the parents in their children's English language and literacy development. Sharing reading activities not only increased social interaction between parents and children, but also between parents and teachers who began to work together more closely. Having access to culturally relevant texts and related activities was also an important factor in increasing opportunities for promoting home and school engagement in reading and writing. Field notes also revealed that parents were working with each other. Sometimes parents were not sure how to interpret the teaching instructions and use activities in the packages. They often called parents who had used the materials previously to find out what they did. Several parents even worked collaboratively to exchange extra texts to read with their sons. Some parents commented that the Literacy package provided fun and playful activities and resources for parents and students to work purposefully. One of the parents indicated, 'My son and I especially liked to complete the reading activities together especially inferring questions, as we challenged each other' In addition, incorporating interesting texts along with colorful pictures provided great benefits that motivated students to read and write . 
The field notes about classroom observation and teachers' logs found that teachers started to realize that there are a variety of reading strategies and instructions that could be used on a daily basis. Teachers often gravitate toward spoon-fed styles of teaching that promote the pattern of rote memorization in students along with worksheets and tests. The field notes also found that participant Math and Science teachers gained a better understanding about a variety of literary forms as they became effective teachers of reading. Thus the fourth hypothesis was positively confirmed.

\section{Discussion}

These results revealed that using mediated cognitive strategies in combination with gradual release of responsibility model improved students' literacy skills, reading and writing and self-efficacy. This result is consistent with those of Brown (2008), Crandall, et al. (2002), Zayyad (2009) and Pajares, Hartley and Valiante (2001) who assured that MCS enhance students' possibilities for experiencing the classroom successes that are so vital to academic motivation and self efficacy.

Moreover, the change in teacher's role, through the GRR model, from an instructor to a facilitator and a language adviser throughout the program allowed students share more responsibilities for their learning. This is consistent with other studies such as fisher's (2006) and Fisher and Frey's (2003). Also, using Mediated cognitive strategies supported with the integration of reading and writing activities, helped students improve their literacy skills. Fiene \& McMahon (2007) and Tompkins (2002) assured that the effective teaching of reading comprehension competencies, which demonstrate higher order thinking and an understanding of the nature of written language e.g. text analysis, generate and answer questions about 
the text, engage in individual silent reading, guided reading and cooperative learning, and monitor their own comprehension, are essential to good writing. These competencies, which demonstrate higher order thinking and an understanding of the nature of written language and how it is used, are also essential to good writing (Grisham \& Wolsey, 2005; Tompkins, 2002). Again, parental involvement proved to be an important asset in developing literacy skills of struggling students at the primary stage. This is consistent with the results of other studies such as the studies of Hammer, Miccio and Wagstaff (2003), Huang (2013) and Lee (2008).

The program had a large effect size on developing the literacy skills as well as self-efficacy. Yet this effect varied from one section to another of the literacy test and the self-efficacy. Also, the effect size of the program on reading self efficacy was more than its effect size on writing self efficacy. This may be attributed to the complexity of the writing skill and its need for longer time of practice and exercise. This result is consistent with Bartle (2005) and Palmer (2010).

In summary, analysis of the quantitative data revealed that the proposed program had a great effect on developing the participants' literacy skills as well as self-efficacy beliefs. This may be attributed to certain features of the program:

- The flexibility of the program reflected in providing various opportunities for guided reading with peers and parents, individual silent reading and group work, using a variety of assigned culturally related and interesting texts.

- Further, the program provides a means for struggling students to receive literacy instruction with some familiarity with the reading 
content, using cultural related interesting texts. This can be important for struggling students for whom entirely novel texts, coupled with poor reading and writing skills, may reinforce disinclination.

- Accompanying these varieties and flexibility in participation structures and practices were exceptional gains in student performance both related (meta-cognitive control) and unrelated (reading new and unfamiliar sight words) measures of reading ability.

- Following the phases of the GRR model throughout the program a pattern of three recognizable discernible stages emerged from the analysis of student-teacher and student-parent interaction patterns: teaching by telling, teaching by modeling and scaffolding, and teaching from behind.

\section{Based on the findings of the study, the following recommendations seem pertinent:}

- More attention should be paid to cognitive based strategies in teaching English literacy mainly at the elementary level.

- Training teachers on co-teaching and gradual release of responsibility models to deal with struggling students is of critical importance.

- Struggling students should be given enough opportunities to practice literacy skills in supportive environment both at school and home.

- Parental involvement is essential in developing literacy skills of primary students, mainly struggling students. So much attention should be paid for supporting the relationship between school staff and parents. 


\section{Suggestions for further research}

- A larger scale study may explore into the effect of parents involvement on students spoken skills.

- Compare different cognitive strategies in terms of their effectiveness in developing students' reading and writing skills.

- Investigate the effect of gradual release of responsibility model on developing spoken skills of primary school students.

- Investigate the effect of team teaching on the achievement level of struggling students.

\section{References}

Anderson, S. (2000). How parental involvement makes a difference in reading achievement. Reading Improvement, 37(2), 61-86.

August, D., \& Shanahan, T. (Eds.). (2006). Developing Literacy in SecondLanguage Learners: Report of the National Literacy Panel on Language-Minority Children and Youth. Mahwah, NJ: Erlbaum. Retrieved From Http://Www.Routledge.Com (accessed on 22/1/ 2015)

Ball, R. (2006). Supporting and involving families in meaningful ways. Young Children, 61(1), 10-11.

Bandura, A. (1997). Self-Efficacy: The Exercise of Control. New York: Longman.

Bartel Virginia (2005). Merging literacies: A case study. Childhood Education, summer 2005, 96-200.

Block, C. C., \& Pressley, M. (Eds.). (2002). Comprehension instruction: Research-based best practices. New York: Guilford Press.

Brown Rachel (2008). The Road Not Yet Taken: A transactional strategies approach to comprehension instruction. The Reading Teacher, 61(7), Pp. 538547, DOI:10.1598/RT.61.7.3 ISSN: 0034-0561 Print / 1936-2714 Online 
Buehl, D. (2005). Scaffolding. Reading Room. Available at: www.weac.Org/News/2005-06/Sept05/Readingroomoct05.Htm accessed on January 2, 2015 from

Chowdury, M. R. (2003). International TESOL training and EFL contexts: the cultural disillusionment factor. Australian Journal of Education, 47(3), 283-303.

Cole, J.E. (2002). What Motivates Students To Read? four literacy personalities. The Reading Teacher, 56, 326-336.

Creswell, J. (2005). Educational research: planning, conducting, and evaluating quantitative and qualitative research. Upper Saddle River, New Jersey: Pearson Merrill Prentice Hall.

Creswell, J. W. (2003). Qualitative procedures in research design: qualitative, quantitative and mixed methods approaches $(2 \mathrm{n}$ ed). Thousand Oaks, CA: SAGE Publications.

Decker, L., Decker, V., \& Brown, P. (2007). Diverse partnerships for student success. Lanham, MD: Rowman \& Littlefield Education.

Dever, M.T., \& Burts, D.C. (2002). An Evaluation of Family Literacy packages As a Vehicle for Parent Involvement. Early Child Development and Care, 172, $359-370$.

Donaldson Rebecca (2011). What classroom observations reveal about primary grade reading comprehension instruction within high poverty schools participating in the Federal reading first initiative. PHD Dissertation, Utah State University, ProQuest UMI Number: 3461336

Donohoo Jenni (2010). addressing adolescent content-area literacy through SiteBased Instructional Coaching. PHD Dissertation, Faculty of Education, University Of Windsor, Canada, ProQuest, UMI Number: 3461254

Duke, N. K., \& Carlisle, J. (2011). The development of comprehension. In M. L. Kamil, P. D. Pearson, E. B. Moje, \& P. P. Afflerbach (Eds.), Handbook of reading research: Volume IV (pp. 199-228). New York, NY: Routledge. 
Epstein, J.L. (2001). School, Family, and Community Partnerships: Preparing Educators and Improving Schools. Boulder, CO: Westview.

Espinosa Linda (2011). Promoting Early Language and Literacy Development of English Language Learners: A Research-Based Agenda, National Early Literacy Panel Concept Paper, 2009, 2010;.

Fiene, J., \& McMahon, S. (2007). Assessing Comprehension: Aclassroom based process. International reading Association 406-417.

Fisher D., and Frey N., (2013). What's The Secret to Successful Close Reading? Strategic Preparation and Follow Up. Reading Today October/November 2013, Pp.16-17

Fisher, D. And Frey N. (2007). "Implementing a School wide literacy framework: improving achievement in an urban elementary school," The Reading Teacher, 61, 2007, Pp. 32-45.

Fisher, D., \& Frey, N. (2003). Writing instruction for struggling adolescent readers: A gradual release model. Journal of Adolescent and Adult Literacy, 46, 396-407.

Frey N., Fisher D., (2010) identifying instructional moves during guided learning. The Reading Teacher, 64(2), Pp. 84-95, DOI:10.1598/RT.64.2.1 ISSN: 0034-0561 Print / 1936-2714 Online

Frey, N. And D. Fisher (2006). Language arts workshop: purposeful reading and writing instruction, Merrill Education, Upper Saddle River, New Jersey, 2006.

Gajria, M., Jitendra, A. K., Sood, S., \& Sacks, G. (2007). Improving comprehension of expository text in students with LD: A research synthesis. Journal of Learning Disabilities, 40(3), 210-225.

Geith, A., (2006). Literacy and English as a foreign language. $25^{\text {th }}$ CDELT National Symposium on English Language Teaching, Ain Shams University, Cairo, Egypt. 
Gong Wengao, Zhang Donglan, Zhang Lawrence, Kiss Tamas And Ang-Tay Yin (2011). Socio-Psychological Factors and Strategy Use in Singaporean Schoolchildren's English Literacy Learning. Reflections on English Language Teaching, 10 (1), Pp. 1-24

Grisham, D. L., \& Wolsey, T.D. (2005). Improving Writing: comparing the responses of eight graders, pre-service teachers and experienced teachers. Reading and Writing Quarterly 21 (4), 315-330.

Guthrie, J. T., \& Davis, M. H. (2003). Motivating struggling readers in middle school through an engagement model of practice. Reading and Writing Quarterly, 19, 59-85.

Guthrie, J. T., Wigfield, A., Barbosa, P., Perencevich, K. C., Taboada, A., Davis, M. H., et al. (2004). Increasing reading comprehension and engagement through concept oriented reading instruction. Journal of Educational Psychology, 96, 403-423.

Hoover-Dempsey, K. V., \& Sandler, H. M. (1995). Parental involvement in children's education: Why does it make a difference? Teachers College Record, 97, 310-331.

Huang Suhua (2013). The Use of Literacy packages Promotes Parental Involvement in Chinese Children's Literacy Learning in the English Language. Language Teaching Research 17(2) 251- 268. SAGE: DOI: $10.1177 / 1362168813475950$

Jitendra, A.K., Chard, D., Hoppes, M.K., Renouf, K., \& Gardill, M.C. (2001). An evaluation of main idea strategy instruction in four commercial reading programs: Implications for students with learning disabilities. Reading \& Writing Quarterly, 17(1), 53-73. doi:10.1080/105735601455738 
Klinger, J. K., \& Vaughn, S. (1996). Reciprocal teaching of reading comprehension strategies for students with learning disabilities who use English as a second language. Elementary School Journal, 96(3), 275-293.

Klingner, J. K., \& Vaughn, S. (2000). The Helping Behaviors of Fifth Graders While Using Collaborative Strategic Reading during ESL Content Classes. TESOL Quarterly, 34(1), 69-98.

Kong, Ailing; Pearson, P David (2003). The Road to Participation: The Construction of A Literacy Practice In A Learning Community of Linguistically Diverse Learners. Research in the Teaching Of English; Aug 2003; 38, 1; ProQuest Education Journals Pg. 85- 124

Lederer, J. M. (2000). Reciprocal Teaching of Social Studies in inclusive Elementary Classrooms. Journal of Leaning Disabilities, 33(1), 91-106.

Lee Yi-Chien (2008). Parental Involvement and Support For Taiwanese Children's English Language And Literacy Learning. Phd Dissertation ProQuest UMI Number: 318119

Marcon, R.A. (1999). Positive Relationships between Parent School Involvement and Public School Inner-City Preschooler's Development and Academic Performance. The School Psychology Review, 28(3), 305-412.

Marzano, R., Pickering, D., \& Pollock, J. (2001). Classroom Instruction That Works. Association for Supervision and Curriculum Development • Alexandria, Virginia USA

National Institute for Literacy (2006). The Early Childhood Longitudinal Study. Available at: http://www.nifl.gov/nifl/facts/ECLS.html. accessed on 11/12/ 2014

Nicolaidou Iolie (2010). Relating Elementary Students' Process Portfolios to Writing Self-Efficacy and Performance. PhD Thesis at Concordia University, Canada. Available on ProQuest database.

\section{1}


Oeideachais A. And Scileanna, A. (2011). Literacy and Numeracy For Learning And Life: The National Strategy To Improve Literacy And Numeracy Among Children And Young People 2011-2020. Published By Department Of Education And Skills Marlborough Street Dublin, Ireland,1

Opitz, M.F., Rubin, D., \& Erekson, J. (2011). Reading diagnosis and improvement: Assessment and instruction. 6th ed. Boston, MA: Pearson.

Pajares, F. (2006). Self-efficacy during childhood and adolescence. Implications for teachers and parents. In F. Pajares \& T. Urdan (Eds.), Self-efficacy and adolescence (pp. 339-367). USA: Information Age Publishing, Inc.

Pajares, F., \& Valiante, G. (1997). The predictive and mediational roles of the writing self-efficacy beliefs of upper elementary school students. Journal of Educational Research, 90, 353-360.

Pajares, F., Hartley, J., \& Valiante, G. (2001). Response format in writing selfefficacy assessment: Greater discrimination increases prediction. Measurement \& Evaluation in Counseling \& Development, 33(4), 214-222.

Palmer M. (2010). The Relationship Between Reading Fluency, Writing Fluency, And Reading Comprehension In Suburban Third-Grade Students. PhD dissertation, Faculty of San Diego State University and the University of San Diego, Proquest, UMI Number: 3435802

Pearson, P. D. And M. C. Gallagher (1983). The Instruction of Reading Comprehension, Contemporary Educational Psychology, 8, Pp. 317-344

Pearson, P. D., \& Dole, J. (1987). Explicit comprehension instruction: A review of research and a new conceptualization of instruction. The Elementary School Journal, 88(2), 151-165.

Piercey R. Richardson (2013). Reading self-efficacy in early adolescence: which measure works best? A PhD dissertation, College of Education, University of Kentucky 
Potenza-Radis Cheryl L. (2008). A Study Examining How Struggling Third Grade Readers, As Members of A Guided Reading Group, Experience Peer-Led Literature Discussions, PHD Dissertation, Kent State University College And Graduate School Of Education, ProQuest, UMI Number: 3335101

Pressley, M. (2002). Comprehension strategies instruction: A turn-of-the-century status report. In C.C. Block \& M. Pressley (Eds.), Comprehension instruction: Research-based best practices (pp. 11-27). New York: Guilford.

Pressley, M. (2006). Reading Instruction That Works: The Case for Balanced Teaching Research Based Strategies for Increasing Student Achievement. Association for Supervision and Curriculum Development. Alexandria, VA.

Roberts, J., Jurgens, J., \& Burchinal, M. (2005). The role of home literacy practices in preschool children's language and emergent literacy skills. Journal of Speech, Language, and Hearing Research, 48, 345-359.

Tompkins, G. E. (2002). Struggling Readers Are Struggling Writers, Too. Reading \& Writing Quarterly, 18(2), 175-193.

Vygotsky, L. S. (1978). Mind in Society. Cambridge, MA: Harvard University Press.

Waanders, C., Mendez, J., \& Downer, J. (2007). Parent characteristics, economic stress, and neighborhood context as predictors of parent involvement in preschool children's education. Journal of School Psychology, 45, 619-636.

Williams, M. (2001). Making Connections: A Workshop For Adolescents Who Struggle with Reading. Journal Of Adolescent \& Adult Literacy, 44, 588-602.

Zayyad Muhammad (2009). The Impact of Mediated Cognitive Strategies on the Reading Comprehension Performance and Self-Efficacy Of Palestinian Arab Middle School Students With Ld: A Mixed-Methods Research. PHD Dissertation, BOSTON COLLEGE, Lynch School of Education, ProQuest: UMI Number: 3387048 
Zimmerman B. J. (2000). Self-efficacy: an essential motive to learn. Contemporary educational psychology 25, 82-91, 2000. Doi: 15010/ceps, 1999, 1016 available at attp://www.idealibrary.com (Accessed on 22/2/2015) 